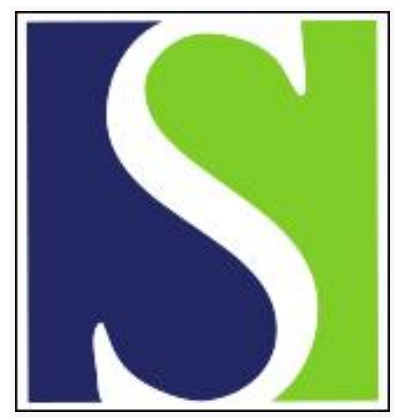

Scand J Work Environ Health 2013;39(6):568-577

https://doi.org/10.5271/sjweh.3374

Published online: 01 Jul 2013, Issue date: 01 Nov 2013

Risk of surgery for subacromial impingement syndrome in relation to neck-shoulder complaints and occupational biomechanical exposures: a longitudinal study

by Svendsen SW, Dalbøge A, Andersen JH, Thomsen JF, Frost P

The impact of occupational biomechanical shoulder exposures on risk of surgery for subacromial impingement syndrome (SIS) is unknown. Shoulder load increased the risk of surgery for SIS. Neck-shoulder complaints combined with high shoulder load conveyed the highest risk.

Affiliation: Danish Ramazzini Centre, University Department of Occupational Medicine, Herning Regional Hospital, GI. Landevej 61, DK-7400 Herning, Denmark. susasven@rm.dk

Refers to the following texts of the Journal: 2004;30(5):399-409 2007;33(3):165-191 2009;35(1):19-36 2010;36(3):189-201 2011;37(6):502-511 2012;38(5):436-446

The following articles refer to this text: 2016;42(6):481-489; 2020;46(3):259-267; 2022;48(6):490-497; 2023;49(1):53-63; 2023;49(2):156-163

Key terms: acromioplasty; force; job exposure matrix; job strain; longitudinal study; neck-shoulder complaint; occupation biomechanical exposure; posture; psychosocial factor; repetitive work; shoulder; subacromial decompression; subacromial impingement syndrome; surgery; work

This article in PubMed: www.ncbi.nlm.nih.gov/pubmed/23811718

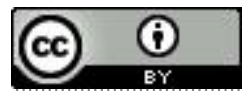




\title{
Risk of surgery for subacromial impingement syndrome in relation to neck-shoulder complaints and occupational biomechanical exposures: a longitudinal study
}

\author{
by Susanne Wulff Svendsen, PhD, ${ }^{1}$ Annett Dalbøge, MSc, ${ }^{2}$ Johan Hviid Andersen, PhD, ${ }^{1}$ Jane Frølund \\ Thomsen, PhD, ${ }^{3}$ Poul Frost, PhD ${ }^{2}$
}

\begin{abstract}
Svendsen SW, Dalbøge A, Andersen JH, Thomsen JF, Frost P. Risk of surgery for subacromial impingement syndrome in relation to neck-shoulder complaints and occupational biomechanical exposures: a longitudinal study. Scand J Work Environ Health. 2013;39(6):568-577. doi:10.5271/sjweh.3374
\end{abstract}

\begin{abstract}
Objectives The aim of this longitudinal study was to evaluate the risk of surgery for subacromial impingement syndrome (SIS) in relation to neck-shoulder complaints and occupational biomechanical shoulder exposures.

Methods The study was based on the Musculoskeletal Research Database at the Danish Ramazzini Centre. We linked baseline questionnaire information from 1993-2004 on neck-shoulder complaints, job titles, psychosocial work factors, body mass index, and smoking with register information on first-time surgery for SIS from 1996-2008. Biomechanical exposure measures were obtained from a job exposure matrix based on expert judgment. We applied multivariable Cox regression.
\end{abstract}

Results During 280125 person-years of follow-up among 37402 persons, 557 first-time operations for SIS occurred. Crude surgery rates increased from 1.1 to 2.5 per 1000 person-years with increasing shoulder load. Using no neck-shoulder complaints and low shoulder load at baseline as a reference, no neck-shoulder complaints and high shoulder load showed an adjusted hazard ratio $\left(\mathrm{HR}_{\mathrm{adj}}\right)$ of $2.55[95 \%$ confidence interval $(95 \%$ CI) 1.59-4.09], while neck-shoulder complaints in combination with high shoulder load showed an $\mathrm{HR}_{\text {adj }}$ of 4.52 (95\% CI 2.87-7.13). Subanalyses based on 18856 persons showed an $\mathrm{HR}_{\text {adj }}$ of 5.40 (95\% CI 2.88-10.11) for complaints located specifically in the shoulder in combination with high shoulder load.

Conclusions Based on these findings, persons with neck-shoulder and especially shoulder complaints in combination with high shoulder load seem an obvious target group for interventions aimed at reducing exposures to prevent surgery for SIS.

Key terms acromioplasty; force; job exposure matrix; job strain; posture; psychosocial factor; repetitive work; shoulder; subacromial decompression; work.

Shoulder complaints with clinical findings presumed to originate from subacromial structures have been designated as subacromial impingement syndrome (SIS) (1). Increasing rates of surgery for SIS have been reported $(2,3)$. In Denmark, a fourfold increase in annual rates of surgery for SIS occurred during 1996-2008, reaching a level of 1.5 per 1000 persons aged 18-63 years; within two years after surgery, the risk of permanent work disability was $9.8 \%$, with low education level as a negative prognostic factor (4). Longitudinal evidence has been established for an association between occupational biomechanical exposures and shoulder complaints (5-7). There is also evidence for an association with clinically diagnosed SIS $(8,9)$, but few longitudinal studies have contributed $(10-13)$. Evidence for an association with rotator cuff tears has been found in a case-control study (14) and in a case series where the distribution of occupations was compared with that of the general population (15). It is unknown, whether occupational biomechanical shoulder exposures are associated with an increased risk of surgery for SIS.

1 Danish Ramazzini Centre, University Department of Occupational Medicine, Herning Regional Hospital, Herning, Denmark.

2 Danish Ramazzini Centre, Department of Occupational Medicine, Aarhus University Hospital, Aarhus, Denmark.

3 Department of Occupational and Environmental Medicine, Bispebjerg Hospital, Copenhagen, Denmark.

Correspondence to: Susanne Wulff Svendsen, Danish Ramazzini Centre, University Department of Occupational Medicine, Herning Regional Hospital, Gl. Landevej 61, DK-7400 Herning, Denmark. [E-mail: susasven@rm.dk] 
Intuitively, neck-shoulder complaints are a likely predictor of SIS, but - except for one study (16) - we are not aware of studies that have confirmed this relationship. It also remains to be shown if persons are at a particular risk of surgery for SIS if they have neck-shoulder complaints in combination with high occupational biomechanical exposures. If this is the case, persons who develop neck-shoulder complaints while having a job that entails high exposures constitute a group where reduction of exposures would be especially warranted.

We have recently established the Musculoskeletal Research Database (MRD) at the Danish Ramazzini Centre as a basis for longitudinal studies of sufficient size to evaluate risk factors for disorders that are severe enough to be treated at hospital and thus become accessible for register linkage. The intention was to bridge the gap between purely register-based studies, which lack information on previous complaints and other potential risk factors, and resource-demanding prospective studies with future results. At present, the MRD comprises questionnaire data from nine previous studies of musculoskeletal symptoms in the Danish working population or selected occupational groups. This is the first study to take advantage of the MRD and a new job exposure matrix (JEM) for the shoulder.

The aim of this longitudinal study was to evaluate the risk of surgery for SIS in relation to neck-shoulder complaints and occupational biomechanical shoulder exposures. We hypothesized that neck-shoulder complaints and occupational biomechanical shoulder exposures would each increase the risk.

\section{Methods}

\section{Study cohort}

Table 1 presents the original studies I-IX (17-28) and their contribution to the MRD, which comprises 39590 persons. A total of 265 persons participated in two studies, and one person participated in three; for these persons, we selected the questionnaire dataset that was most informative for the present study. We excluded persons who were $<18$ or $\geq 70$ years old at start of follow-up $(\mathrm{N}=2$ and $\mathrm{N}=109$, respectively), underwent any kind of shoulder surgery between 1 January 1996 and start of follow-up according to the Danish National Patient Register (29) ( $\mathrm{N}=115)$, died or emigrated before start of follow-up according to the Danish Civil Registration System $(\mathrm{N}=31)$, or were missing baseline information on occupational title $(\mathrm{N}=263)$ or neck-shoulder complaints $(\mathrm{N}=1668)$. Studies I and IV in table 1 comprised historical cohorts; we retrieved information on permanent transfer incomes at baseline from the Danish National Register on
Public Transfer Payments to allow subanalyses, excluding persons who had left the labor market. The Danish Data Protection Agency authorized the MRD and the present study. In Denmark, register and questionnaire studies do not require approval by committees on biomedical research ethics.

\section{Outcome}

During follow-up, we identified first-time operations for SIS in the Danish National Patient Register. The register contains data on all admissions to public somatic hospitals since 1977 and outpatient contacts since 1995. Visits to private hospitals have been registered since 2001, but reporting from private hospitals was not compulsory until 15 September 2007; before 2000, shoulder surgery in private hospitals was rare in Denmark (4). The outcome included surgery performed under a main diagnosis in the International Classification of Diseases, $10^{\text {th }}$ revision, groups M75.1- M75.9 (rotator cuff syndrome, bicipital tendinitis, calcific tendinitis, impingement syndrome, bursitis, and other and unspecified shoulder disorders) or M19 (other arthrosis) without a subordinate diagnosis of M75.0 (adhesive capsulitis of shoulder) and registered with one or more Danish Nordic Medico-Statistical Committee (NOMESCO) shoulder and upper-arm surgery codes in the groups KNBA (exploratory procedures), $\mathrm{KNBE}$ and $\mathrm{KNBF}$ (procedures on synovia and ligaments), $\mathrm{KNBG}, \mathrm{KNBH}$, and KNBK (acromioplasty), and KNBL and KNBM (procedures on bursae and tendons).

\section{Neck-shoulder complaints}

The original studies VIII and IX in table 1 asked: "How much have you been bothered by pain or complaints in your neck or shoulders within the past 12 months?" (not at all, very little, a little, somewhat, quite a lot, much, very much). Study V asked the same question for neck and shoulders separately. The remaining studies used Nordicstyle questions: "What is the total length of time that you have had neck (/shoulder) pain or complaints during the last 12 months?" (five or six response categories), only study I asked about pain or complaints during the last 12 months (no/yes). We classified patients as having neckshoulder complaints if they had been at least somewhat bothered by neck-shoulder symptoms, reported neck and/or shoulder symptoms for $\geq 8$ days within the last 12 months, or answered yes to at least one no/yes question. In subanalyses, we used specific information on shoulder complaints from the seven studies that allowed this.

\section{Occupational biomechanical shoulder exposures}

We constructed a shoulder JEM and allocated exposure estimates to each participant by combining self-reported 
Table 1. Description of nine original studies (reference) that have contributed to the Musculoskeletal Research Database (MRD) at the Danish Ramazzini Centre.

\begin{tabular}{|c|c|c|c|c|c|c|}
\hline \multirow[t]{2}{*}{ Study } & & \multirow{2}{*}{$\begin{array}{l}\text { Baseline } \\
\text { year }\end{array}$} & \multirow{2}{*}{$\begin{array}{c}\text { Original } \\
\text { proportion } \\
\text { who } \\
\text { responded } \\
(\%)\end{array}$} & \multirow{2}{*}{$\begin{array}{l}\text { Original } \\
\text { number of } \\
\text { respondents }\end{array}$} & \multicolumn{2}{|c|}{$\begin{array}{c}\text { Participants in } \\
\text { MRD a }^{\text {a }}\end{array}$} \\
\hline & & & & & $\mathrm{N}$ & $\begin{array}{c}\% \\
\text { women }\end{array}$ \\
\hline I & The Nurses' Aides Study (17) & 1993 & 74 & 4616 & 4612 & 98 \\
\hline II & Project on Deboning in Pig Slaughterhouses (18) & 1993 & 82 & 2463 & 2119 & 7 \\
\hline III & Project on Research and Intervention in Monotonous work, the PRIM health study $(19,20)$ & 1994 & 75 & 3123 & 2964 & 58 \\
\hline IV & Project on Shoulder Disorders and Postural Load Factors (21) & 2000 & $\geq 70$ & 2053 & 2053 & 0 \\
\hline V & Neck and Upper extremity Disorders Among Technical Assistants, the NUDATA study $(22,23)$ & 2000 & 73 & 6943 & 6942 & 63 \\
\hline VI & Project on Work at Institutions for Adults with Disabilities (24) & 2001 & 72 & 799 & 362 & 82 \\
\hline VII & Project on Cleaners and Shop Assistants (25) & 2001 & 89 & 2704 & 2558 & 100 \\
\hline VIII & The FAUST study of employees at 39 work sites $(26,27)$ & 2002 & 71 & 4006 & 4005 & 62 \\
\hline IX & The ASUSI study of a working population sample (28) & 2004 & 70 & 14241 & 14241 & 49 \\
\hline
\end{tabular}

a The MRD comprises 39590 unique persons, of whom 265 participated in two of the original studies and one participated in three. Civil registration system numbers were not always available, which explains why not all the original participants were included in the database.

baseline information on occupational title with exposures from the JEM. To construct the JEM, we excluded 185 obsolete or very rare occupational titles from the 2227 occupational titles in the Danish version of the International Standard Classification of Occupations (D-ISCO 88) and divided the remainder into 172 groups of jobs that were expected to have similar exposure profiles regarding computer use and the exposures mentioned below. We then selected 11 job groups that covered a wide range of exposures. Five experienced occupational health physicians consensus-rated these 11 groups so that they could serve as benchmarks, which allowed the experts to calibrate their estimates to a common scale (30). For each of the job groups that were left, the experts independently rated (i) the mean force exerted with the hand and arm across a full working day relative to the maximal strength of a "standard person" (a healthy 35 -year-old male), using a 5-point force-score scale $(0=$ light, $1=$ somewhat hard, $2=$ hard, $3=$ very hard, $4=$ near maximal) (31). The experts also rated the mean number of hours per working day (in half-hour intervals) with (ii) upper-arm elevation $>90^{\circ}$, and (iii) moderately and highly repetitive work ( $\geq 4-<15$ and $\geq 15$ movements of the upper arm per minute, respectively).

The benchmarks and the mean values of the experts' ratings were included in the JEM. We categorized the force-score as $<1.5, \geq 1.5-<2.5$, or $\geq 2.5$, the duration of upper-arm elevation $>90^{\circ}$ as $0,>0-<1$, or $\geq 1$ hours/ day, and repetitive work as moderately repetitive work $<2, \geq 2-<4, \geq 4$ hours/day, or highly repetitive work. The last-mentioned category was chosen in case of highly repetitive work $\geq 0.5$ hours/day, but among persons who fulfilled this criterion, $94 \%$ had a duration which was $\geq 6$ hours/day and the duration was $\geq 3$ hours/day for the remaining persons. We also calculated a joint exposure measure. Persons were classified as having high shoulder load if they fulfilled at least one of the following criteria: a force-score $\geq 3$, upper-arm elevation $>90^{\circ} \geq 1$ hours/day, highly repetitive work $\geq 0.5$ hours/day, and moderately repetitive work $\geq 4$ hours/day. Persons were classified as having medium shoulder load if they performed highly repetitive work $<0.5$ hours/day and fulfilled at least one of the following criteria: a force-score $>1.5-<3$, upper-arm elevation ${ }^{\circ} \geq 0.5-<1$ hours/day, and moderately repetitive work $\geq 2-<4$ hours/day. Those, who fulfilled all of the following criteria, were classified as having low shoulder load: a force-score $\leq 1.5$, upperarm elevation $>90^{\circ}<0.5$ hours/day, highly repetitive work $<0.5$ hours/day, and moderately repetitive work $<2$ hours/day. Furthermore, we subdivided the group with high shoulder load into three categories depending on the number of high exposures (force-score, upper-arm elevation, repetitive work).

\section{Psychosocial work and other potential risk factors}

All questionnaires asked about psychosocial work factors based on the Karasek-Theorell three-factor model. Studies V, VIII, and IX (table 1) asked global single-item questions on job demands, job control, and social support at work, eg: "How demanding do you feel your job is all in all?" (six response categories). The remaining studies used multi-item scales (four or five response categories). With regard to job demands and job control, global single items and corresponding multi-item scales have been found to measure the same constructs (32). To combine single- and multi-item scales, we recoded the multi-item scales to global scales ranging from 1 (good) to 6 (bad). We then dichotomized the resulting variables at the median. Smoking status (never smoker, ex-smoker, current smoker) was available from all the studies with the exception of studies II and VII, and height and weight were available from all the studies with the exception of study II. We calculated body 
mass index (BMI) as weight / height square $\left(\mathrm{kg} / \mathrm{m}^{2}\right)$. Furthermore, we used information on sex, age, and original study.

Education level was assessed based on unemployment insurance fund membership at baseline according to the Danish National Register on Public Transfer Payments. In the MRD, this information was missing for 748 persons, for whom we assessed education level based on D-ISCO 88 codes, and for 316 persons who received cash benefit (a part of the lowest level of the social safety net in Denmark). We categorized education level as higher/medium, vocational, and low (4); persons who received cash benefit were included in the low category. A priori, we decided not to include education level in the main analyses to avoid over-adjustment due to correlations with occupational biomechanical exposures.

\section{Statistical analysis}

We used multivariable Cox regression analyses stratified by original study and calculated hazard ratios (HR) with $95 \%$ confidence intervals ( $95 \% \mathrm{CI}$ ). Follow-up time was calculated from 1 January 1996 or from the date when the questionnaire was completed, whichever came last, until the date of first-time surgery for SIS or censoring due to other types of shoulder surgery, emigration, age 70 (to allow five years of follow-up after the usual Danish retirement age of 65 years), death, or end of follow-up by 31 December 2008, whichever came first. We ensured that the proportional hazards assumption was met by means of a global test, which also comprised a variable-by-variable test $(33,34)$. Additionally, we checked if comparable results were found in three separate time periods (19962001, 2002-2006, and 2007-2008). Likelihood-ratio tests were used to examine interactions between neckshoulder complaints and shoulder load and between job demands and job control (job strain) (35). We addressed the problem of missing information on BMI and smoking status in specific studies using the likelihood-ratio test to compare the model including these variables and the corresponding model excluding them in analyses, which left out study II and - with respect to smoking status also study VII. To check that our results were consistent across original studies and questionnaire styles (Nordic versus other), we performed supplementary, unstratified analyses, which included original study and questionnaire style, respectively.

To estimate the potential for prevention, we calculated the excess fraction of cases among the exposed by multiplying the aetiologic fraction, $\left(\mathrm{HR}_{\mathrm{adj}}-1\right) / \mathrm{HR}_{\mathrm{adj}}$ for medium and high shoulder load, respectively, by the number of operations within each of these exposure categories, then summing up the excess numbers, and finally dividing the sum by the total number of operations among the exposed and converting to percent. Analyses were carried out with STATA 12 software (StataCorp LP, College Station, TX, USA).

\section{Results}

The study cohort comprised 37402 persons, 15845 men and 21557 women, who represented 1131 occupational titles, 929 among men and 696 among women. The most frequent occupational titles with high shoulder load were slaughterhouse workers, car mechanics, house painters, poultry workers, and carpenters among men, and cleaners, poultry workers, slaughterhouse workers, sewing-machine operators, and postal workers among women, accounting for $71 \%$ and $86 \%$ of jobs with high shoulder load among men and women, respectively. Of 9559 persons with high shoulder load, $23 \%$ had one high exposure, $53 \%$ had two, and $24 \%$ had three (slaughterhouse workers and wood industry workers). The most frequent jobs with medium shoulder load were machinists, technical assistants, and farmers/agricultural workers among men and nurses' aides, nurses, and childcare workers among women.

Table 2 lists baseline characteristics of the study cohort according to shoulder load. Job control, social support at work, and education level showed skewed distributions; the correlation coefficient between shoulder load and education level was 0.76 . The percentages that received permanent transfer incomes at baseline were $2.1 \%, 3.4 \%$, and $6.1 \%$ for participants with low, medium, and high shoulder load, respectively. The mean age [standard deviation (SD)] in these exposure categories was 43.1 (SD 10.1), 43.9 (SD 9.9), and 43.6 (SD 11.5), respectively. The one-year prevalence of neck-shoulder complaints was $45 \%$ : $35 \%$ among men and 53\% among women. Across categories of increasing shoulder load, the prevalence of neck-shoulder complaints among men increased from $27 \%$ to $33 \%$ to $43 \%$. The corresponding percentages for women were $47 \%, 57 \%$, and $57 \%$. Specific information on shoulder complaints was available for 20094 persons, and 40\% reported such complaints within the past 12 months, $29 \%$ among men and $45 \%$ among women; neck complaints were present for $24 \%$ of those who did not report shoulder complaints.

During 280125 person-years of follow-up, 557 firsttime operations for SIS occurred, corresponding to an incidence rate of 2.0 per 1000 person-years, 2.1 among men and 1.9 among women. The mean follow-up time was 7.5 years. In the time periods 1996-2001, 20022006, and 2007-2008, the mean age of cases was 48, 50 , and 50 years, respectively. Among persons censored due to age, only one person was operated later, at age 73 . 
Table 2. Baseline characteristics of the study cohort ( $N=37402)$ according to shoulder load, a joint measure of occupational mechanical exposures.

\begin{tabular}{|c|c|c|c|c|c|c|}
\hline & \multicolumn{6}{|c|}{ Shoulder load } \\
\hline & \multicolumn{2}{|c|}{$\begin{array}{c}\text { Low } \\
\mathrm{N}=15758\end{array}$} & \multicolumn{2}{|c|}{$\begin{array}{c}\text { Medium } \\
\mathrm{N}=12085\end{array}$} & \multicolumn{2}{|c|}{$\begin{array}{c}\text { High } \\
\mathrm{N}=9559\end{array}$} \\
\hline & $\mathrm{N}$ & $\%$ & $\mathrm{~N}$ & $\%$ & $\mathrm{~N}$ & $\%$ \\
\hline \multicolumn{7}{|l|}{ Sex } \\
\hline Women & 9847 & 62 & 8320 & 69 & 3390 & 35 \\
\hline Men & 5911 & 38 & 3765 & 31 & 6169 & 65 \\
\hline \multicolumn{7}{|l|}{ Smoking status } \\
\hline Never smoker & 6963 & 44 & 4159 & 34 & 1568 & 16 \\
\hline Ex-smoker & 3964 & 25 & 2891 & 24 & 1299 & 14 \\
\hline Current smoker & 4203 & 27 & 4614 & 38 & 2573 & 27 \\
\hline Missing & 628 & 4 & 431 & 4 & 4119 & 43 \\
\hline \multicolumn{7}{|l|}{ Body mass index } \\
\hline$<25 \mathrm{~kg} / \mathrm{m}^{2}$ & 9283 & 59 & 7296 & 60 & 3707 & 39 \\
\hline$\geq 25-<30 \mathrm{~kg} / \mathrm{m}^{2}$ & 4745 & 30 & 3468 & 29 & 2817 & 29 \\
\hline$\geq 30 \mathrm{~kg} / \mathrm{m}^{2}$ & 1378 & 9 & 1033 & 9 & 887 & 9 \\
\hline Missing & 352 & 2 & 288 & 2 & 2148 & 23 \\
\hline \multicolumn{7}{|l|}{ Job demands } \\
\hline Low & 10245 & 65 & 7223 & 60 & 5583 & 58 \\
\hline High & 5389 & 34 & 4061 & 34 & 3886 & 41 \\
\hline Missing & 124 & 1 & 801 & 7 & 90 & 1 \\
\hline \multicolumn{7}{|l|}{ Job control } \\
\hline High & 10069 & 64 & 5246 & 43 & 2855 & 30 \\
\hline Low & 5525 & 35 & 6010 & 50 & 6575 & 69 \\
\hline Missing & 164 & 1 & 829 & 7 & 129 & 1 \\
\hline \multicolumn{7}{|l|}{ Social support at work } \\
\hline $\begin{array}{l}\text { From leaders and } \\
\text { colleagues }\end{array}$ & 7558 & 48 & 5574 & 46 & 2150 & 22 \\
\hline From leaders, only & 1155 & 7 & 616 & 5 & 1514 & 16 \\
\hline From colleagues, only & 2830 & 18 & 2629 & 22 & 1229 & 13 \\
\hline No social support & 3919 & 25 & 2313 & 19 & 4391 & 46 \\
\hline Missing & 296 & 2 & 953 & 8 & 275 & 3 \\
\hline \multicolumn{7}{|l|}{ Education level } \\
\hline Higher/medium & 14102 & 90 & 3200 & 26 & 360 & 4 \\
\hline Vocational & 1185 & 8 & 7255 & 60 & 2587 & 27 \\
\hline Low & 471 & 3 & 1630 & 13 & 6612 & 69 \\
\hline
\end{tabular}

Overall, $13 \%(\mathrm{~N}=73)$ of the operations were performed in private hospitals, ranging from $11 \%$ in the groups with medium and high shoulder load to $22 \%$ in the group with low shoulder load. From 1996-2001, no private hospital operations occurred; from $2002-2006,11 \%$ of the operations were performed in private hospitals, and from 2007-2008, the percentage was $27 \%$. Table 3 presents the risk of surgery for SIS in relation to specific occupational biomechanical exposures and shoulder load. There was a significantly increasing trend with increasing exposures. Crude surgery rates increased from 1.1 to 2.5 per 1000 person-years with increasing shoulder load, and a trend analysis for an increment of one category of shoulder load showed an $\mathrm{HR}_{\text {adj }}$ of $1.42(95 \%$ CI 1.17-1.71). When we restricted the analyses to participants in the labor market at baseline, results did not change. Based on the observed number of cases among participants with medium and high shoulder load, respectively, and the corresponding $\mathrm{HR}_{\mathrm{adj}}$ in table 3, the excess fraction of cases among the exposed was $43 \%$, distributed with $26 \%, 39 \%$, and $46 \%$ in the time periods 1996-2001, 2002-2006, and 20072008 , respectively (period-specific $\mathrm{HR}_{\text {adj }}$ not shown).

Table 4 presents risk of surgery for SIS in relation to combinations of neck-shoulder complaints and forceful work, work with elevated arms, and repetitive work. Each of these exposures increased the risk of surgery, both among participants without neck-shoulder complaints and among participants with such complaints. Neck-shoulder complaints combined with high exposures conveyed the highest risks.

Table 5 displays risk of surgery for SIS in relation to combinations of neck-shoulder complaints and shoulder load. BMI and smoking status did not contribute significantly to the adjusted model $(\mathrm{P}=0.38)$. The $\mathrm{HR}_{\mathrm{adj}}$ was 4.52 for neck-shoulder complaints combined with high shoulder load. The correlation coefficient between education level and the variable that combined neckshoulder complaints and shoulder load was 0.42 . Inclusion of education level in the adjusted model reduced the HR but did not change the overall pattern of associations - eg, for neck-shoulder complaints combined with high shoulder load, inclusion of education level reduced the $\mathrm{HR}_{\text {adj }}$ to 3.10 (95\% CI 1.86-5.17). Separate results for men and women were similar to those for the total cohort (results not shown). No interaction was seen between job demands and job control $(\mathrm{P}=0.22)$. Supplementary, unstratified analyses, which included the original study and questionnaire style, respectively, did not reveal any significant effects of these factors (results not shown). Subanalyses based on 18856 persons showed an $\mathrm{HR}_{\mathrm{adj}}$ of $5.40(95 \%$ CI 2.88-10.11) for complaints located specifically in the shoulder in combination with high shoulder load (the remainder of the 20094 persons with specific information on shoulder complaints missed other relevant information). For the same subpopulation, the maximum $\mathrm{HR}_{\text {adj }}$ for neck-shoulder complaints in combination with high shoulder load was $4.90(95 \%$ CI 2.54-9.42).

\section{Discussion}

This longitudinal study of 37402 persons showed that a force-score of $\geq 2.5$ points, upper-arm elevation $>90^{\circ}$ for $\geq 1$ hours/day, and highly repetitive work for $\geq 3$ hours/day entailed an approximately doubled risk of surgery for SIS. With increasing shoulder load, crude surgery rates increased from 1.1 to 2.5 per 1000 person-years. The excess fraction of cases among the exposed was $43 \%$. When compared to participants with no neck-shoulder complaints and low shoulder load, neck-shoulder complaints in combination with high shoulder load carried a four-fold risk, and the risk was 
Table 3. Risk of surgery for subacromial impingement syndrome in relation to specific occupational biomechanical exposures and shoulder load. Results of Cox regression analyses including one exposure variable at a time and stratified by original study. [95\% $\mathrm{Cl}=95 \%$ confidence interval; $\mathrm{HR}_{\mathrm{adj}}=$ adjusted hazard ratio]

\begin{tabular}{|c|c|c|c|c|c|}
\hline Exposure & Cases & Person-years at risk & $\mathrm{HR}_{\text {crude }}{ }^{\mathrm{a}}$ & $\mathrm{HR}_{\mathrm{adj}}^{\mathrm{b}}$ & $95 \% \mathrm{Cl}$ \\
\hline \multicolumn{6}{|l|}{ Forceful work (force-score) } \\
\hline$<1.5$ points & 136 & 111554 & 1 & 1 & .. \\
\hline$\geq 1.5-<2.5$ points & 282 & 113441 & 1.52 & 1.52 & $1.11-2.07$ \\
\hline$\geq 2.5$ points & 139 & 55131 & 2.22 & 1.74 & $1.16-2.64$ \\
\hline \multicolumn{6}{|l|}{ Arm elevation $>90^{\circ}$} \\
\hline 0 hours/day & 274 & 154856 & 1 & 1 & .. \\
\hline$>0-<1$ hour/day & 127 & 64689 & 1.60 & 1.53 & $1.14-2.05$ \\
\hline$\geq 1$ hour/day & 156 & 60581 & 1.98 & 1.61 & $1.06-2.45$ \\
\hline \multicolumn{6}{|l|}{ Repetitive work } \\
\hline Moderately repetitive work <2 hours/day & 353 & 193648 & 1 & 1 & .. \\
\hline Moderately repetitive work $\geq 2-<4$ hours/day & 35 & 16119 & 1.20 & 1.20 & $0.78-1.83$ \\
\hline Moderately repetitive work $\geq 4$ hours/day & 75 & 33382 & 1.41 & 1.34 & $0.88-2.05$ \\
\hline Highly repetitive work & 94 & 36976 & 1.87 & 1.76 & $1.05-2.96$ \\
\hline \multicolumn{6}{|l|}{ Shoulder load } \\
\hline Low & 115 & 100792 & 1 & 1 & .. \\
\hline Medium & 236 & 96682 & 1.63 & 1.64 & $1.19-2.26$ \\
\hline High & 206 & 82651 & 2.18 & 1.96 & $1.33-2.89$ \\
\hline
\end{tabular}

a Adjusted for age, which was used as the underlying time variable. Number of observations: 37402 .

b Adjusted for job demands, job control, social support at work, sex, smoking status, body mass index, and age, which was used as the underlying time variable. Number of observations: 29962.

Table 4. Risk of surgery for subacromial impingement syndrome in relation to combinations of neck-shoulder complaints and specific occupational biomechanical exposures. Results of Cox regression analyses including one exposure variable at a time and stratified by original study. [95\% $\mathrm{Cl}=95 \%$ confidence interval; $\mathrm{HR}_{\mathrm{adj}}=$ adjusted hazard ratio]

\begin{tabular}{|c|c|c|c|c|c|}
\hline Complaints and exposure & Cases & Person-years at risk & $\mathrm{HR}_{\text {crude }^{\mathrm{a}}}$ & $H R_{\text {adj }}{ }^{j}$ & $95 \% \mathrm{Cl}$ \\
\hline No complaints - force-score $<1.5$ points & 46 & 64266 & 1 & 1 & \\
\hline No complaints - force-score $\geq 1.5-<2.5$ points & 60 & 50628 & 1.47 & 1.45 & $0.93-2.28$ \\
\hline No complaints - force-score $\geq 2.5$ points & 57 & 28840 & 3.13 & 2.01 & $1.15-3.53$ \\
\hline Complaints - force-score $<1.5$ points & 90 & 47287 & 2.69 & 2.66 & $1.82-3.89$ \\
\hline Complaints - force-score $\geq 1.5-<2.5$ points & 222 & 62813 & 4.26 & 4.23 & $2.79-6.42$ \\
\hline Complaints - force-score $\geq 2.5$ points & 82 & 26291 & 4.79 & 4.05 & $2.42-6.77$ \\
\hline No complaints - arm elevation $>90^{\circ} 0$ hours/day & 63 & 75563 & 1 & 1 & . \\
\hline No complaints - arm elevation $>90^{\circ}>0-<1$ hours/day & 39 & 38138 & 1.43 & 1.41 & $0.90-2.20$ \\
\hline No complaints - arm elevation $>90^{\circ} \geq 1$ hours/day & 61 & 31034 & 2.66 & 2.15 & $1.23-3.74$ \\
\hline Complaints - arm elevation $>90^{\circ} 0$ hours/day & 211 & 80293 & 2.61 & 2.74 & $2.00-3.79$ \\
\hline Complaints - arm elevation $>90^{\circ}>0-<1$ hours/day & 88 & 26551 & 4.68 & 4.43 & $3.01-6.52$ \\
\hline Complaints - arm elevation $>90^{\circ} \geq 1$ hour/day & 95 & 29547 & 4.25 & 3.38 & $1.99-5.74$ \\
\hline No complaints - moderately repetitive work $<2$ hours/day & 92 & 100554 & 1 & 1 & . \\
\hline No complaints - moderately repetitive work $\geq 2$ hours/day & 29 & 24878 & 1.21 & 1.31 & $0.79-2.17$ \\
\hline No complaints - highly repetitive work & 42 & 18303 & 3.14 & 3.03 & $1.53-6.03$ \\
\hline Complaints - moderately repetitive work $<2$ hours/day & 261 & 93095 & 2.77 & 2.92 & $2.21-3.84$ \\
\hline Complaints - moderately repetitive work $\geq 2$ hours/day & 81 & 24623 & 3.45 & 3.31 & $2.17-5.04$ \\
\hline Complaints - highly repetitive work & 52 & 18673 & 3.60 & 3.62 & $1.95-6.72$ \\
\hline
\end{tabular}

adjusted for age, which was used as the underlying time variable. Number of observations: 37402.

${ }^{\mathrm{b}}$ Adjusted for job demands, job control, social support at work, sex, smoking status, body mass index, and age, which was used as the underlying time variable. Number of observations: 29962. 
Table 5. Risk of surgery for subacromial impingement syndrome in relation to combinations of neck-shoulder complaints and shoulder load, psychosocial work factors, and sex, while adjusting for age; body mass index and smoking status did not contribute significantly to the adjusted model. Results of Cox regression analyses stratified by original study. $\left[95 \% \mathrm{Cl}=95 \%\right.$ confidence interval; $\mathrm{HR}_{\mathrm{adj}}=\mathrm{adjusted}$ hazard ratio]

\begin{tabular}{|c|c|c|c|c|c|}
\hline Risk factors & Cases & Person-years at risk & $\mathrm{HR}_{\text {crude }}{ }^{\mathrm{a}}$ & $\mathrm{HR}_{\mathrm{adj}}^{\mathrm{b}}$ & $95 \% \mathrm{Cl}$ \\
\hline No complaints - low shoulder load & 36 & 58716 & 1 & 1 & .. \\
\hline No complaints - medium shoulder load & 53 & 43209 & 1.80 & 1.58 & $0.99-2.51$ \\
\hline No complaints - high shoulder load & 74 & 41811 & 3.06 & 2.55 & $1.59-4.09$ \\
\hline Complaints - low shoulder load & 79 & 42077 & 3.08 & 3.02 & $2.02-4.52$ \\
\hline Complaints - medium shoulder load & 183 & 53473 & 4.83 & 4.66 & $3.05-7.12$ \\
\hline Complaints - high shoulder load & 132 & 40841 & 5.40 & 4.52 & $2.87-7.13$ \\
\hline \multicolumn{6}{|l|}{ Job demands } \\
\hline Low & 294 & 168550 & 1 & 1 & .. \\
\hline High & 230 & 101379 & 1.21 & 1.13 & $0.94-1.36$ \\
\hline \multicolumn{6}{|l|}{ Job control } \\
\hline High & 170 & 115516 & 1 & 1 & .. \\
\hline Low & 355 & 153986 & 1.42 & 1.22 & $1.00-1.50$ \\
\hline Job demands $\times$ job control (interaction term) & . & . & . & $1.28^{c}$ & $0.86-1.89$ \\
\hline \multicolumn{6}{|l|}{ Social support at work } \\
\hline From leaders and colleagues & 196 & 111332 & 1 & 1 & .. \\
\hline From leaders, only & 47 & 28078 & 0.78 & 0.70 & $0.49-0.99$ \\
\hline From colleagues, only & 110 & 50236 & 1.16 & 1.02 & $0.80-1.29$ \\
\hline No social support & 167 & 76662 & 1.10 & 0.91 & $0.71-1.17$ \\
\hline \multicolumn{6}{|l|}{ Sex } \\
\hline Male & 241 & 112563 & 1 & 1 & .. \\
\hline Female & 316 & 167562 & 0.80 & 0.77 & $0.60-0.99$ \\
\hline
\end{tabular}

adjusted for age, which was used as the underlying time variable. Number of observations: 37402.

${ }^{b}$ Mutually adjusted for all variables in the table and for age, which was used as the underlying time variable. Number of observations: 35574.

c Likelihood-ratio test $\mathrm{P}=0.22$.

more than five-fold for complaints located specifically in the shoulder in combination with high shoulder load.

Several of the original studies in the MRD have been rated as being among the highest quality studies in international reviews of occupational risk factors for shoulder (9) and other musculoskeletal (36-39) disorders. Additionally, the present study benefited from the fact that the MRD represents large exposure contrasts when compared to general population samples of comparable size, which increased the power of the study to detect effects of high, but less prevalent exposures. A methodological limitation was that, in general, we did not have information on non-responders. However, responses were obtained from $\geq 70 \%$ in all the original studies (table 1), and we stratified the analyses by original study to account for differences between studies regarding participation at baseline as well as assessment of psychosocial variables and neck-shoulder complaints.

We used an expert-based JEM to obtain exposure estimates independently of the symptom status of the participants. If we had relied on self-reported exposure estimates, recall bias could have inflated the associations. Four of the original studies (II, III, IV, and V in table 1) included observations or technical measurements of shoulder exposures. The experts knew the results of these exposure assessments when they rated the job groups for the JEM, which presumably increased the validity of their ratings, and our findings of exposure-response relations indicated that the JEM had a high predictive validity. However, the experts' ratings were not validated against other exposure estimates, which means that the results may not accurately reflect the risk of surgery associated with the exact exposure categories that we applied. We are currently addressing this issue using technical measurements.

The shoulder load variable was constructed to capture the joint biomechanical exposure, which could be due to any of the three generic exposures (forceful work, work with elevated arms, repetitive work) or a combination of two or all three of them. Since risks associated with one or more exposures were lumped together, analyses using the variable might underestimate risks associated with combined exposures. However, $77 \%$ of the participants with high shoulder load had a combination of at least two exposures.

We assumed that exposures did not change markedly after baseline. However, among participants with neck-shoulder complaints, a slight decline in $\mathrm{HR}_{\text {adj }}$ was observed when exposures increased from medium to high force-scores and durations of arm elevation, which was not observed among participants without neck-shoulder complaints (table 4). This suggests a healthy worker selection, which may have caused us to underestimate exposure-related risks of surgery for SIS. 
The one-year prevalence of neck-shoulder complaints was $45 \%$, which agreed with previously reported general population means of $40 \%(40,41)$, considering the composition of the cohort. Baseline shoulder complaints could have been part of the indication for surgery rather than a predictor of SIS leading to surgery. However, the risk of surgery would then be expected to decrease with time since baseline, which was contradicted by the fact that we found proportional hazards.

Denmark has a public and free healthcare system, which minimizes socioeconomic differences in access to surgery, and we think that our results can be generalized to other countries with easy access to surgery for SIS. Still, our results suggested that persons with low shoulder load had easier access to private treatment. Since private hospitals did not have to report to the Danish National Patient Register until 2007, we may have underestimated surgery rates especially among persons with low shoulder load, and thus overestimated associations with exposures. In that case, the excess fraction of cases among the exposed would be expected to be lower in 2007-2008 than in the preceding period; we observed quite the opposite. Moreover, selective underreporting of around 100 cases in the group with low shoulder load would be necessary to eliminate the association, which seems unrealistic (cf. table 3). Another aspect is that persons with medium and high shoulder load may have had to fulfill tighter indications for surgery, in which case we underestimated what their surgery rates would have been had they had equal access to treatment.

The relations between exposures and risk of surgery for SIS could be due to an increased risk of SIS or a higher probability of surgery given SIS. Persons with high exposures depend on a good shoulder function to continue to work, and in case of SIS they may be more likely to seek treatment. On the other hand, surgeons may expect a poorer prognosis for patients, who intend to return to highly exposed jobs, and in particular, they may be reluctant to offer surgery in case of workers' compensation claims, which have been linked with a poorer prognosis $(42,43)$. Irrespective of the extent to which our results reflected an increased risk of SIS or a higher probability of surgery given SIS, the findings of the present study, combined with the previously reported risk of permanent work disability after surgery (4), suggest that persons with low education level and/ or high shoulder load have an increased risk of surgery and an increased risk of subsequent work disability. In our opinion, such a combination of risks calls for preventive measures.

\section{Concluding remarks}

In conclusion, this longitudinal study showed that forceful work, work with elevated arms, and repetitive work each carried a doubled risk of surgery for SIS, and that persons with neck-shoulder complaints in combination with high shoulder load had a four-fold risk, when compared to participants with no neck-shoulder complaints and low shoulder load. The risk was more than five-fold for complaints located specifically in the shoulder in combination with high shoulder load. Based on this, we think that persons, who develop neck-shoulder and especially shoulder complaints while having a job with high biomechanical shoulder exposures, constitute an obvious target group for interventions to reduce exposures in order to prevent surgery for SIS.

\section{References}

1. Huisstede BM, Miedema HS, Verhagen AP, Koes BW, Verhaar JA. Multidisciplinary consensus on the terminology and classification of complaints of the arm, neck and/or shoulder. Occup Environ Med. 2007;64(5):313-9. http://dx.doi. org/10.1136/oem.2005.023861.

2. Nordqvist A, Rahme H, Hovelius L, Etzner M. Axelns sjukdomar [Shoulder diseases]. Läkartidningen. 2007;104(19):1492-6.

3. Vitale MA, Arons RR, Hurwitz S, Ahmad CS, Levine WN The rising incidence of acromioplasty. J Bone Joint Surg Am. 2010;92(9):1842-50. http://dx.doi.org/10.2106/ JBJS.I.01003.

4. Svendsen SW, Frost P, Jensen LD. Time trends in surgery for non-traumatic shoulder disorders and postoperative risk of permanent work disability: a nationwide cohort study. Scand J Rheumatol. 2012;41(1):59-65. http://dx.doi.org/10.3109/0 3009742.2011.595375.

5. Bodin J, Ha C, Sérazin C, Descatha A, Leclerc A, Goldberg $\mathrm{M}$, et al. Effects of individual and work-related factors on incidence of shoulder pain in a large working population. J Occup Health. 2013;54(4):278-88. http://dx.doi.org/10.1539/ joh.11-0262-OA.

6. Herin F, Vezina M, Thaon I, Soulat JM, Paris C. Predictors of chronic shoulder pain after 5 years in a working population. Pain. 2012;153(11):2253-9. http://dx.doi.org/10.1016/j. pain.2012.07.024.

7. Mayer J, Kraus T, Ochsmann E. Longitudinal evidence for the association between work-related physical exposures and neck and/or shoulder complaints: a systematic review. Int Arch Occup Environ Health. 2012;85(6):587-603. http://dx.doi. org/10.1007/s00420-011-0701-0.

8. Roquelaure Y, Bodin J, Ha C, Petit Le MA, Descatha A, Chastang JF, et al. Personal, biomechanical, and psychosocial risk factors for rotator cuff syndrome in a working population. Scand J Work Environ Health. 2011;37(6):502-11. http:// dx.doi.org/10.5271/sjweh.3179.

9. van Rijn RM, Huisstede BM, Koes BW, Burdorf A. Associations between work-related factors and specific 
disorders of the shoulder - a systematic literature review. Scand J Work Environ Health. 2010;36(3):189-201. http://dx.doi. org/10.5271/sjweh.2895.

10. Bodin J, Ha C, Petit Le MA, Serazin C, Descatha A, Leclerc A, et al. Risk factors for incidence of rotator cuff syndrome in a large working population. Scand J Work Environ Health. 2012;38(5):436-46. http://dx.doi.org/10.5271/sjweh.3285.

11. Bodin J, Ha C, Chastang JF, Descatha A, Leclerc A, Goldberg $\mathrm{M}$, et al. Comparison of risk factors for shoulder pain and rotator cuff syndrome in the working population. Am J Ind Med. 2012;55(7):605-15. http://dx.doi.org/10.1002/ ajim.22002.

12. Miranda H, Punnett L, Viikari-Juntura E, Heliovaara M, Knekt P. Physical work and chronic shoulder disorder. Results of a prospective population-based study. Ann Rheum Dis. 2008;67(2):218-23. http://dx.doi.org/10.1136/ ard.2007.069419.

13. Werner RA, Franzblau A, Gell N, Ulin SS, Armstrong TJ. A longitudinal study of industrial and clerical workers: predictors of upper extremity tendonitis. J Occup Rehabil. 2005;15(1):37-46. http://dx.doi.org/10.1007/s10926-0050872-1.

14. Seidler A, Bolm-Audorff U, Petereit-Haack G, Ball E, Klupp M, Krauss N, et al. Work-related lesions of the supraspinatus tendon: a case-control study. Int Arch Occup Environ Health. 2011;84(4):425-33. http://dx.doi.org/10.1007/s00420-0100567-6.

15. Rolf O, Ochs K, Bohm TD, Baumann B, Kirschner S, Gohlke F. Rotatorenmanschettendefekt - eine Berufserkrankung? Eine epidemiologische Analyse [Rotator cuff tear--an occupational disease? An epidemiological analysis]. Z Orthop Ihre Grenzgeb. 2006;144(5):519-23. http://dx.doi. org/10.1055/s-2006-942240.

16. Descatha A, Chastang JF, Cyr D, Leclerc A, Roquelaure Y, Evanoff B. Do workers with self-reported symptoms have an elevated risk of developing upper extremity musculoskeletal disorders three years later? Occup Environ Med. 2008;65(3):205-7. http://dx.doi.org/10.1136/ oem.2007.033357.

17. Jensen LD, Ryom PK, Christensen MV, Andersen JH. Differences in risk factors for voluntary early retirement and disability pension: a 15-year follow-up in a cohort of nurses' aides. BMJ Open. 2012;2(6).

18. Udbeningsarbejde i svineslagterier [Deboning in pig slaughterhouses]. København: Arbejdsmiljøinsituttet; 1996.

19. Frost P, Bonde JP, Mikkelsen S, Andersen JH, Fallentin N, Kærgaard A, et al. Risk of shoulder tendinitis in relation to shoulder loads in monotonous repetitive work. Am J Ind Med. 2002;41(1):11-8. http://dx.doi.org/10.1002/ajim.10019.

20. Andersen JH, Kaergaard A, Mikkelsen S, Jensen UF, Frost $\mathrm{P}$, Bonde JP, et al. Risk factors in the onset of neck/shoulder pain in a prospective study of workers in industrial and service companies. Occup Environ Med. 2003;60(9):649-54. http:// dx.doi.org/10.1136/oem.60.9.649.

21. Svendsen SW, Bonde JP, Mathiassen SE, Stengaard-Pedersen
K, Frich LH. Work related shoulder disorders: quantitative exposure-response relations with reference to arm posture. Occup Environ Med. 2004;61:844-53. http://dx.doi. org/10.1136/oem.2003.010637.

22. Andersen JH, Harhoff M, Grimstrup S, Vilstrup I, Lassen CF, Brandt LP, et al. Computer mouse use predicts acute pain but not prolonged or chronic pain in the neck and shoulder. Occup Environ Med. 2008;65(2):126-31. http://dx.doi.org/10.1136/ oem.2007.033506.

23. Brandt LP, Andersen JH, Lassen CF, Kryger A, Overgaard E, Vilstrup I, et al. Neck and shoulder symptoms and disorders among Danish computer workers. Scand J Work Environ Health. 2004;30(5):399-409. http://dx.doi.org/10.5271/ sjweh.828.

24. Jensen LD, Giver H, Andersen JS. Arbejdsmiljø og helbred blandt ansatte inden for voksenhandicapområdet i Århus Amt - en 2-årig opfølgningsundersøgelse på 23 institutioner i Århus Amt [Working environment and health among employees at institutions for adults with disabilities in Aarhus County - a 2-year follow-up study at 23 institutions in Aarhus County]. København: Arbejdsmiljøinstituttet; 2006.

25. Bonde JP, Jensen LD. Arbejdsmiljø og helbred hos rengøringsassistenter i Århus Amt. En undersøgelse af sammenhænge mellem øvre bevægeapparatssymptomer og -lidelser ved professionelt rengøringsarbejde [Working environment and health among cleaners in Aarhus County. A study of neck and upper extremity musculoskeletal symptoms and disorders in relation to professional cleaning work]. Århus: Arbejdsmedicinsk Klinik i Århus; Kvindeligt Arbejderforbund i Danmark; 2004.

26. Andersen JH, Haahr JP, Frost P. Risk factors for more severe regional musculoskeletal symptoms: a two-year prospective study of a general working population. Arthritis Rheum. 2007;56(4):1355-64. http://dx.doi.org/10.1002/art.22513.

27. Frost P, Haahr JP, Andersen JH. Reduction of pain-related disability in working populations: a randomized intervention study of the effects of an educational booklet addressing psychosocial risk factors and screening workplaces for physical health hazards. Spine. 2007;32(18):1949-54. http:// dx.doi.org/10.1097/BRS.0b013e3181342659.

28. Hansen CD, Andersen JH. Sick at work--a risk factor for longterm sickness absence at a later date? J Epidemiol Community Health. 2009;63(5):397-402. http://dx.doi.org/10.1136/ jech.2008.078238.

29. Lynge E, Sandegaard JL, Rebolj M. The Danish National Patient Register. Scand J Public Health. 2011;39(7 Suppl):30-3. http://dx.doi.org/10.1177/1403494811401482.

30. Teschke K, Olshan AF, Daniels JL, De Roos AJ, Parks CG, Schulz M, et al. Occupational exposure assessment in case-control studies: opportunities for improvement. Occup Environ Med. 2002;59(9):575-93. http://dx.doi.org/10.1136/ oem.59.9.575

31. Moore JS, Garg A. The Strain Index: a proposed method to analyze jobs for risk of distal upper extremity disorders. Am Ind Hyg Assoc J. 1995;56(5):443-58. http://dx.doi. org/10.1080/15428119591016863. 
32. Kristensen TR. Sickness absence. The importance of socioeconomic status, job strain, iso-strain and effort-reward imbalance. Department of Occupational and Environmental Medicine, Bispebjerg Hospital, University of Copenhagen, Denmark; 2010.

33. Grambsch PM, Therneau TM. Proportional hazards tests and diagnostics based on weighted residuals. Biometrika. 1994;81(3):515-26. http://dx.doi.org/10.1093/ biomet/81.3.515 .

34. Schoenfeld D. Partial residuals for the proportional hazards regression model. Biometrika. 1982;69(1):239-41. http:// dx.doi.org/10.1093/biomet/69.1.239 .

35. Mikkelsen S, Bonde JP, Andersen JH. Analysis of job strain effects. Occup Environ Med. 2011;68(10):786. http://dx.doi. org/10.1136/oemed-2011-100203.

36. Palmer KT, Smedley J. Work relatedness of chronic neck pain with physical findings--a systematic review. Scand J Work Environ Health. 2007;33(3):165-91. http://dx.doi. org/10.5271/sjweh.1134 .

37. van Rijn RM, Huisstede BM, Koes BW, Burdorf A. Associations between work-related factors and the carpal tunnel syndrome--a systematic review. Scand J Work Environ Health. 2009;35(1):19-36. http://dx.doi.org/10.5271/ sjweh.1306.

38. van Rijn RM, Huisstede BM, Koes BW, Burdorf A Associations between work-related factors and specific disorders at the elbow: a systematic literature review.
Rheumatology (Oxford). 2009;48(5):528-36. http://dx.doi. org/10.1093/rheumatology/kep013.

39. Wai EK, Roffey DM, Bishop P, Kwon BK, Dagenais S. Causal assessment of occupational lifting and low back pain: results of a systematic review. Spine J. 2010;10(6):554-66. http:// dx.doi.org/10.1016/j.spinee.2010.03.033.

40. Fejer R, Kyvik KO, Hartvigsen J. The prevalence of neck pain in the world population: a systematic critical review of the literature. Eur Spine J. 2006;15(6):834-48. http://dx.doi. org/10.1007/s00586-004-0864-4.

41. Côté P, van der Velde G, Cassidy JD, Carroll LJ, Hogg-Johnson $\mathrm{S}$, Holm LW, et al. The burden and determinants of neck pain in workers: results of the Bone and Joint Decade 2000-2010 Task Force on Neck Pain and Its Associated Disorders. J Manipulative Physiol Ther. 2009;32(2 Suppl):S70-S86. http:// dx.doi.org/10.1016/j.jmpt.2008.11.012.

42. American Academy of Orthopaedic surgeons (AAOS) Optimizing the management of rotator cuff problems. Rosemont (IL): American Academy of Orthopaedic Surgeons (AAOS); 2010.

43. Johannsen HV, Andersen NH, Søjbjerg JO, Sneppen O. Artroskopisk subakromial dekompression [Arthroscopic subacromial decompression]. Ugeskr Laeger. 1997;159(2):166-70.

Received for publication: 15 April 2013 